\title{
TERAPIA COMUNITÁRIA SISTÊMICA E INTEGRATIVA COMO INSTRUMENTO DE AVALIAÇÃO E DIAGNÓSTICO DA SAÚDE DE SERVIDORES DA SECRETARIA DE EDUCAÇÃO DE UBERABA-MG
}

\author{
Ralph CASTRO* \\ Cinara Aline FREITAS ${ }^{* *}$ \\ Eliete Pereira RODRIGUES ${ }^{* *+}$ \\ Maurino Bertoldo SILVA ${ }^{* * *}$
}

RESUMO: A categoria docente é exposta a ambientes conflituosos, alta exigência e estresse, repercutindo na saúde física, mental e no desempenho destes profissionais. Em levantamento realizado na Secretaria Municipal de Educação de Uberaba-MG (SEMED), os problemas de saúde mental e osteomusculares são responsáveis por quase metade de todos os afastamentos. Estes fatores guardam relação intrínseca ao sistema de trabalho, stress, sobrecarga e baixa qualidade de vida. Este estudo procura compreender as principais causas de sofrimento dos professores, segundo a voz, expressão e opinião dos mesmos. Foram realizadas dez sessôes de Terapia Comunitária Sistêmica e Integrativa (TCSI) em dez escolas com a partici-

\footnotetext{
* Nutricionista Especialista em Docência Universitária. Analista Governamental da Secretaria de Educação de Uberaba. Coordenador do Curso de Formação em Terapia Comunitária Uberaba, Araxá e Uberlândia. Formador em Terapia Comunitária - UFC Universidade Federal do Ceará. Uberaba - MG - Brasil. 38025-140 - ralph.castro@ uberabadigital.com.br

** Psicopedagoga e Analista de Gestấo Educacional da Secretaria de Educação. Uberaba MG - Brasil.38061-080 - cínara.freitas@uberabadigital.com.br

*** Bióloga Professora de Educação Básica da Secretaria de Educação. Uberaba - MG Brasil. 38061-080 - elieterodriguesvisa@gmail.com

**** Teólogo, Psicólogo Clínico, Organizacional e do Trabalho, Terapeuta Comunitário. Psicólogo. IPREM - Instituto de Previdência. Governador Valadares - MG - Brasil. 35020160. Administrador da Lux Centro Avançado de Pesquisa e Serviços em Saúde. Governador Valadares - MG - Brasil. 35020-020 - maurinobertoldo@yahoo.com.br
} 
pação de 296 profissionais. Olhando para a rede de atendimento e suporte à saúde do professor é possível perceber que o acolhimento ofertado aos professores da rede municipal é eficiente no que diz respeito ao tratamento do indivíduo, porém deixa a desejar em relação ao acolhimento coletivo. Nesse sentido, surge a indagação "se o sujeito adoece socialmente por que tratá-lo individualmente?”. Os resultados apontam que a TCSI pode fazer parte de projetos mais amplos voltados à compreensão dos sofrimentos coletivos, à saúde do trabalhador e para futuramente contribuir na elaboração de políticas públicas de instituiçôes de ensino.

PALAVRAS-CHAVE: Saúde mental. Adoecimento docente. Terapia comunitária integrativa sistêmica.

\section{Introduçáo}

O profissional da educaçáo enquanto "categoria docente" é uma das mais expostas a ambientes conflituosos e de alta exigência, tais como docência, tarefas extraclasse, reuniōes, funçóes administrativas, atividades adicionais, orientaçóes de alunos problemas (com relatos de ameaças verbais e físicas), bem como limitação de tempo para realizar as atividades. Além disso, está inserido num contexto de mudanças em que alteraçóes ambientais (políticas, econômicas, sociais e culturais) e as pressóes decorrentes sobre determinadas tarefas têm alterado experiências de trabalho e seus significados. Essa situação estressante leva a repercussões na saúde física e mental e no desempenho destes profissionais.

Miller (1992) afirma que esses fatos afetam a estrutura psíquica dos indivíduos e Dejours (1988) aponta a docência como uma profissão de sofrimento. Os desgastes físico e mental, ocasionados pelas exigências permanentes da profissão docente, trazem certamente, impactos em termos de bem-estar e saúde para a maioria dos profissionais da categoria.

Esteve (1989) identificou cinco grandes mudanças sociais que impuseram certa pressáo aos professores e que criaram condiçóes para o aumento dos estudos sobre stress na categoria. São elas:

- A transformação do papel do professor e dos agentes tradicionais de integraçáo social;

- As crescentes contradiçóes no papel do professor;

- As mudanças nas atitudes da sociedade em torno do professor;

- A incerteza acerca dos objetivos do sistema educacional e da longevidade ou utilidade do conhecimento; 
- A deterioração da imagem do professor.

A partir de um estudo realizado na Secretaria Municipal de Educação e Cultura de Uberaba-MG (SEMEC) analisa-se que as principais causas de afastamentos dos servidores apontam os problemas de saúde mental e osteomusculares como responsáveis por quase metade dos afastamentos e por mais da metade do número de dias afastados. Estes fatores guardam relação intrínseca ao sistema de trabalho, stress, sobrecarga e baixa qualidade de vida.

Segundo Maia (2002) existe a interação entre o sistema imunológico e o sistema nervoso e endócrino. Esteve (1999) traça uma sequência de sintomas e quadros clínicos comuns no processo de adoecimento docente. $\mathrm{O}$ estudo desse autor confirma os resultados encontrados ao analisar os principais motivos de adoecimento docente na rede municipal do município de Uberaba/MG, podendo resumir as escala de adoecimento em 3 passos: adoecimento das vias aéreas superiores; adoecimentos sistema osteomuscular e adoecimento por transtornos mentais. Neste trabalho, a título conceitual, consideramos que neste momento histórico, saúde é um estado de razoável harmonia entre o sujeito e a sua própria realidade.

A SEMEC conta com 64 unidades de ensino, entre unidades urbanas e rurais. As escolas atendem crianças a partir dos 6 meses de idade na educação infantil e a alunos no ensino fundamental. Para atender a essa demanda e promover um ensino de qualidade, a SEMEC possui um quadro total de 3997 servidores. Pensando em proporcionar uma melhor qualidade de vida aos seus servidores, esta secretaria se sente corresponsável pelos seus, e não poderia deixar de fomentar o "cuidado" com aqueles que têm como missão formar novos cidadáos.

Com intuito de dar voz e acolher o sofrimento dos professores da rede municipal a SEMEC de Uberaba abriu espaço para a realização de sessôes de Terapia Comunitária Sistêmica e Integrativa (TCSI) em escolas da rede municipal. A escolha da TCSI acorreu por esta prática considerar que todos os indivíduos de uma comunidade, no caso a comunidade escolar, são responsáveis pela busca de soluçôes e a superação dos problemas. De acordo com Barreto (2005) a comunidade que tem o problema tem a solução. Desta forma a TCSI pode integrar os diversos saberes e contextos socioculturais ampliando as redes solidárias de promoçáo da saúde e cidadania. Além disso, a TCSI rompe com estratégias verticais e descontextualizadas por ser um espaço de partilha de experiências de forma horizontal e circular. 
Nas sessôes de TCSI as soluçôes nascem do grupo, por isso a prática favorece a autoconfiança coletiva e o sentimento de inclusáo e pertencimento (identidade) dos indivíduos da comunidade. Além disso, nas sessôes, o sofrimento humano é entendido como uma fonte geradora de competência e por isso deve ser valorizado, resgatado e utilizado como instrumento para crescimento do indivíduo e comunidade.

Este estudo é fruto da realização de 10 sessôes de TCSI em escolas municipais do Município de Uberaba-MG, com intuito de ouvir e compreender as principais causas de sofrimento dos professores do município, segundo a opiniáo dos mesmos.

O objetivo desta pesquisa é compreender as principais causas de sofrimento dos professores da rede municipal de Uberaba-MG, segundo a voz, expressão e opinião dos mesmos. Pretende-se ainda, identificar os principais problemas enfrentados pelos professores da rede municipal e determinar as principais estratégias de enfrentamento dos problemas pelos professores da rede municipal de Uberaba-MG.

\section{Metodologia}

Foram realizadas dez (10) sessóes de TCSI em dez (10) escolas da rede municipal de Uberaba-MG com intenção de apontar os principais problemas, sentimentos e estratégias de enfrentamento dos professores da rede municipal de Uberaba-MG. Além disso, também foi realizada uma sessão de terapia comunitária apenas com diretores das escolas. No total participaram das sessóes 296 professores e diretores da rede municipal. As rodas foram realizadas por terapeutas formadores, professores do Curso de Terapia Comunitária de Uberaba, e contaram com a presença de terapeutas em formação, alunos do curso. O curso foi ofertado em 2013/2014 como atividade de extensão pela Universidade Federal do Triângulo Mineiro - UFTM. As aulas eram ministradas por formadores do Polo Formador em Terapia Comunitária MISC dos Vales de Governador Valadares com o apoio da PRODESU (Projeto, Organização e Desenvolvimento Sustentável). As sessóes foram organizadas seguindo a metodologia desenvolvida pelo Departamento de Medicina Comunitária da Universidade Federal do Ceará (UFC), criada pelo Prof. Dr. Adalberto de Paula Barreto e descrita no livro "Terapia Comunitária passo a passo" de Barreto (2005) conforme esquema a seguir:

- Acolhimento: boas vindas, celebração da vida e regras;

- Escolha do tema: apresentaçáo dos temas, identificaçáa do grupo com os temas apresentados, votaçáo e escolha do tema; 
- Contextualização: coletar informaçóes para compreender o tema eleito;

- Problematização: Mote. Redimensionar seu sofrimento e descobrir que sua dor é a dor de muitos. A situação trazida pelo protagonista faz emergir situaçôes semelhantes já vivenciadas, suas respectivas estratégias de superação e socialização das estratégias de enfrentamento;

- Conclusão: Conotação positiva e socialização do que foi apreendido.

Em todas as sessóes realizadas houve a preocupação em registrar todos os temas relatados, todos os sentimentos despertados e todas as estratégias de enfrentamento da comunidade. Ao final de cada sessão, a equipe de terapeutas (Formadores e terapeutas em formação) se reunia com a finalidade de avaliar as atividades, registrar e organizar os dados. Ao fim das sessōes de TCSI todos os dados foram classificados, organizados e apresentados para profissionais e gestores da secretaria de educação do município.

\section{Resultados}

No total foram realizadas dez (10) sessóes de TCSI com professores e uma (1) sessão de TCSI com diretores da rede municipal de UberabaMG. Ao reunir e analisar todos os dados relativos aos problemas relatados nas sessóes foi possível perceber e destacar que todos os temas poderiam ser classificados em cinco (5) grupos apresentados de forma decrescente:

$1^{\circ}$ - Problemas relativos ao sistema de trabalho (principal queixa dos professores);

$2^{\circ}$ - Problemas relativos à família;

$3^{\circ}$ - Baixo salário;

$4^{\mathrm{o}}$ - Problemas relativos ao relacionamento com alunos;

$5^{\circ}$ - Questóes pessoais.

Em relaçáa aos problemas do sistema de trabalho os principais sentimentos despertados foram: frustração, impotência diante de problemas no trabalho, sobrecarga e falta de qualidade de vida, silêncio (3 rodas), descrença e decepção, tristeza, autocobrança, falta de qualidade de vida, desmotivação, falta de reconhecimento e incompreensão. Quando arguidos sobre os problemas com a família, os principais problemas foram relativos a conflito familiar, morte ou adoecimento de familiares. 
No que diz respeito aos problemas com baixo salário, os sentimentos relatados foram insegurança e desvalorização. Já a respeito da relação com alunos, os principais sentimentos foram insatisfação e desrespeito. Sobre as questóes pessoais que apareceram nas sessóes, os principais sentimentos apontados foram: culpa por magoar o outro, falsidade, traição, obesidade, problema de saúde ou medo de morrer, agonia, impaciência e nervosismo.

Em linhas gerais os principais sentimentos relatados em todas as sessóes foram: frustração, impotência (problemas de trabalho), desvalorização, descrença, desrespeito, desmotivado, desespero, agonia, impaciência, nervosismo, sobrecarga, cobrança, insegurança (baixo salário), medo (baixo salário), insatisfação, autocobrança, culpa, traição, ansiedade e decepção.

Frente a tantos problemas e sentimentos despertados, professores e diretores foram perguntados sobre suas estratégias de enfrentamento, sendo elas: como principal forma de enfrentamento, o fortalecimento e empoderamento pessoal; a segunda estratégia mais utilizada foi busca de redes solidárias (amigos, vizinhos etc.); a ajuda religiosa foi a terceira estratégia de enfrentamento mais frequente nas sessóes, a ajuda profissional apenas em quarto lugar como estratégia de enfrentamento dos problemas relatados.

\section{Discussáo}

Analisando os resultados obtidos é possível perceber que as queixas em relação ao sistema de trabalho aparecem como principal fonte de sofrimentos dos participantes. O sistema de trabalho dos professores da rede municipal de Uberaba é apontado como principal fator gerador de sentimentos como frustração, impotência, desvalorização, sobrecarga e descrença no trabalho. Chama atenção que em três (3) das dez (10) escolas os professores ficaram em silêncio quando houve espaço para falarem sobre seus problemas. O silêncio dos servidores fala a favor do sentimento de descrença no sistema, a crença de que nada será mudado e que todos os problemas dependem de vontade política e de figuras superiores hierarquicamente.

Ampliando o olhar para a rede de acolhimento e suporte à saúde oferecida aos professores é possível perceber que existe a concepção presente nas escolas, de modo geral, de que o adoecimento docente configura-se como algo de responsabilidade individual, não percebendo, ainda, que o indivíduo náo é o único responsável por ser portador de um sintoma ou de seu sofrimento, mas sim que existem relaçóes que mantêm este sinto- 
ma. O esquema abaixo intitulado "ciclo da descrença" demonstra como os sentimentos de frustração, desmotivação e descrença no sistema de trabalho é alimentado e fortalecido nos professores da rede.

\section{Esquema 1 - Ciclo da Descrença}

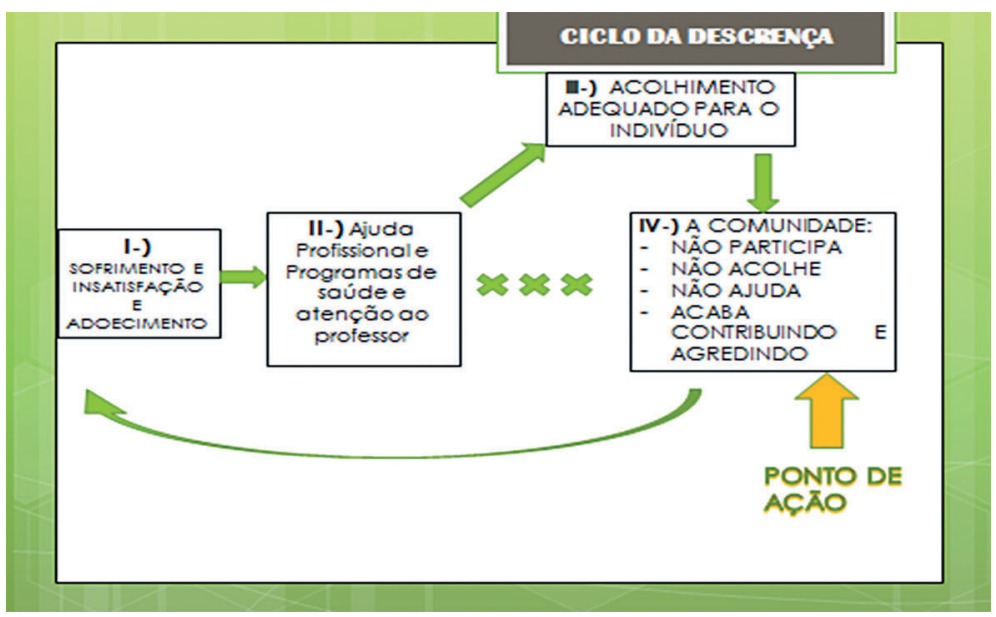

Fonte: Elaboração própria.

O esquema revela que o sistema de acolhimento ofertado aos professores da rede municipal é eficiente no que diz respeito ao acolhimento e tratamento do indivíduo, pois dispóe de plano de saúde para o servidor, bem como atividades terapêuticas na Casa do Servidor e na Casa do Educador, porém deixa a desejar em relação ao acolhimento coletivo. Desta forma, o servidor passa a fazer parte de um ciclo de adoecimento, acolhimento, volta ao ambiente adoecedor e novamente ao estado de sofrimento e adoecimento. $\mathrm{O}$ servidor encarcerado nessa dinâmica, e nutrido por um sentimento de impotência diante ao sistema de trabalho, desiste de lutar e fica mudo diante da realidade. Nesse sentido, o professor que é por essência, um ser político e questionador, adquire um olhar cansado sobre o seu cotidiano de trabalho e não consegue promover as transformaçóes necessárias. Nesse sentido, remetemo-nos a Paulo Freire (1979, p.8): “[...] se a possibilidade de reflexão sobre si, sobre seu estar no mundo, associada indissoluvelmente à sua ação sobre o mundo, não existe no ser, seu estar no mundo se reduz a um náo poder transpor os limites que lhes sáo impostos pelo próprio mundo, do que resulta que este ser não é capaz de compromisso." 
Olhando para o esquema acima surge a indagação "se o sujeito adoece socialmente por que tratá-lo individualmente?” Uma das explicaçóes pode ser encontrada na base conceitual dos cursos de formação que, em geral, é pautada em disciplinas fragmentadas e conhecimentos isolados, justificando assim, uma concepção cartesiana de encarar as dimensôes humanas e sociais. Em contrapartida, a visão sistêmica significa pensar nas relaçôes, padrôes e contexto. Nesse entendimento, há um compartilhamento de propriedades e princípios organizacionais entre todos os sistemas vivos, construindo dessa forma, um sentido comunitário (CAPRA et al., 2006).

Atender individualmente o sujeito que adoece socialmente, além de não produzir resultados duradouros e causar prejuízos ao servidor e aos cofres públicos, contribui para desmotivar todos os envolvidos no sistema. Essa realidade aponta para a necessidade de fomentar estratégias de acolhimento coletivo como a TCSI.

Outro fator que contribui para aumentar o sentimento de descrença e desmotivaçáo é o baixo salário, que impede o professor de ter acesso a atividades de lazer e relaxamento táo importantes para lidar com a sobrecarga e o estresse da atividade docente. Além disso, a baixa remuneraçáo está associada a sentimentos de desvalorização e medo de não conseguir se sustentar, principalmente após a aposentadoria. Aqui, é preciso lembrar, que qualidade de vida guarda relação direta com o grau de independência do indivíduo. Para Ferrans e Power (1992), uma das referências fundamentais para avaliação da qualidade de vida seria a satisfação, ressaltando ainda, que a satisfação com a vida abrangeria elementos de relaçôes familiares e sociais, performance física e desenvolvimento profissional. Há uma crescente associação às questôes de dependência e autonomia articuladas à satisfação e qualidade de vida.

Outro resultado que chama atenção é o fato da ajuda profissional aparecer como a quarta estratégia de enfrentamento dos problemas. Este resultado vincula-se ao sentimento de descrença no sistema de trabalho que, para o servidor, é frio e incompreensivo. Na hora de enfrentar os problemas o servidor prefere enfrentá-los sozinho, buscar a ajuda de amigos, vizinhos ou a igreja antes de procurar a ajuda profissional. Estes dados ajudam a entender porque existe o sentimento de descrença no sistema como um todo, e os sentimentos de impotência e de que nada mudará. Outro ponto importante é que amigos, vizinhos e conhecidos podem náo ter preparo para acolher e compreender o sofrimento do servidor, gerando ainda mais sofrimento e conflito. 
Em linhas gerais é possível argumentar, a princípio, que as estratégias utilizadas tanto pela SEMEC quanto pelos indivíduos pouco interferem no coletivo e consequentemente produzem resultados pouco eficientes no sentido de promover a saúde da coletividade e dos indivíduos que a constituem.

\section{Consideraçóes finais (desafios / o que fazer / propostas)}

No cenário atual as escolas e instituiçóes de ensino devem, cada vez mais, debater e compreender que a solução dos problemas está no coletivo e em suas INTERAÇÓES. A criação de espaços de partilha, de identificação com o outro e respeito às diferenças parece ser importante na promoçáo da saúde da coletividade e dos indivíduos. Em outras palavras, os problemas coletivos devem ser enfrentados coletivamente. Esta percepção ajuda a compreender a TCSI como importante estratégia para atender as demandas coletivas, respondendo à demanda necessária nas instituiçôes. Além disso, a TCSI é um espaço onde o servidor pode falar de si e não apenas de problemas técnicos, o que torna a TCSI uma proposta de promoção da saúde e combate ao estresse e adoecimento do professor.

Este estudo permite pensar que além de atender as demandas dos adoecimentos individuais, as açôes voltadas à saúde do servidor também devem ser focadas na saúde e no espaço coletivo. A escola precisa ser entendida como comunidade, como um ente dotado de: características, interaçôes, necessidades e potencialidades específicas a cada unidade. Neste sentido, as estratégias de promoção da saúde da comunidade escolar devem: acolher para humanizar, escutar para compreender e descentralizar para ser eficiente e aproveitar melhor os recursos públicos.

Parece importante que a TCSI faça parte de projetos mais amplos voltados à compreensão dos sofrimentos coletivos, à saúde do trabalhador e para futuramente contribuir na elaboração de politicas públicas de instituiçóes de ensino. Além disto, trata-se de uma prática atraente do ponto de vista custo benefício, por não exigir grandes investimentos ou gastos com pessoal, material, energia, estrutura física, mídias e recursos financeiros. Vale destacar que para a realização das dez (10) sessôes de TCSI, atendendo 296 professores e diretores, a prefeitura disponibilizou um Terapeuta Comunitário (devidamente certificado) e material de anotaçáo (caneta e papel). Estes argumentos devem ser considerados principalmente em países em desenvolvimento, como é o caso do Brasil, para superar as dificuldades impostas pela falta de recursos. Estratégias e práticas efi- 
cazes e de baixo custo, devem ser encorajadas no sentido de promover a participaçáo coletiva e superar as dificuldades cotidianas dos professores da rede pública.

O desafio para utilização da TCSI como estratégia de avaliação e diagnóstico da saúde de servidores (em diversas áreas) está em superar as barreiras impostas pelos poderes e pela formação baseada na fragmentação do conhecimento, principalmente de gestores, diretores e cargos de chefia.

\author{
INTEGRATIVE AND SYSTEMIC COMMUNITY \\ THERAPY AS AN INSTRUMENT FOR EVALUATION \\ AND DIAGNOSIS OF SERVERS HEALTH FROM \\ UBERABA-MG DEPARTMENT OF EDUCATION
}

ABSTRACT: The teaching category is exposed to conflicting environments, high demand and stress, affecting the physical and mental health and performance of these professionals. In a survey conducted at the Municipal Uberaba-MG Education (SEMED), the problems of mental and musculoskeletal health account for nearly half of all departures. These factors keep intrinsic relationship to the working system, stress, overload and low quality of life. This study seeks to understand the main causes of suffering of teachers, according to the voice, expression and opinion of ten sessions were held of Community Therapy Systemic and integrative (TCSI) in ten schools with the participation of 296 professionals. Looking for network service and support to teacher health you can see that the host offered to teachers of the municipal network is efficient with regard to the treatment of the individual, but is weak in relation to the collective welcoming. In this sense, the question arises if the subject falls ill socially why treat it individually. The results show that the TCSI can be part of broader projects aimed at understanding the collective sufferings, to workers' health and to further contribute to the development of public educational institutions policies.

KEYWORDS: Mental health. Lecturer illness. Integrative and systemic community therapy. 


\section{REFERÊNCIAS}

BARRETO, A. Terapia comunitária passo a passo. Fortaleza: Gráfica LCR, 2005.

CAPRA, F. et al. Alfabetizaçáo ecológica: a educação das crianças para um mundo sustentável. São Paulo: Cultrix, 2006.

DEJOURS, C. A loucura do trabalho: estudo de psicopatologia do trabalho. São Paulo: Cortez, 1988.

ESTEVE, J. M. O mal-estar docente: a sala de aula e a saúde dos professores. Tradução de Durley de Carvalho Cavicchia. Bauru: EDUSC, 1999.

ESTEVE, J. M. Teacher burnout and teacher stress. In: COLE, M.; WALKER, S. (Ed.). Teaching and stress. Milton Keynes: Open University Press, 1989. p.4-25.

FERRANS, C.; POWERS, M. Psychometric assessment of the Quality of Life Index. Research in Nursing and Health, New York, v.15, n.1, p.29-38, 1992.

FREIRE, P. Educaçáo e mudança. 12.ed. Rio de Janeiro: Paz e Terra, 1979.

MAIA, A. Emoçôes e sistema imunológico: um olhar sobre a Psiconeuroimunologia. Psicologia: Teoria, Investigação e Prática, Portugal, v.2, p.207-225, 2002.

MILLER, H. The state of the academic profession. England: The University of Aston in Birmingham, 1992. 
